\title{
Developing an Attitude Scale for Discussion Ability of Pre-service Teachers
}

\author{
Gürbüz OCAK ${ }^{*}$ \\ Gülçin KARAKUŞ ${ }^{* *}$
}

Received: 18 June 2013

Accepted: 26 August 2014

\begin{abstract}
In this study, developing a scale to measure the attitudes towards the discussion ability of pre-service teachers indented. The application scale of the discussion ability was developed in the direction of the pre-service teachers. The scale is likert-type comprising of 57 items. The validity and reliability of the scale is done on the data gained from 200 students elected by the method of coincidental exemplification amount of the sophomore students. As a result of the factorial validity of the scale, items change between 0.59 and 0.76 and that the KMO Kaiser-Meyer-Olkin value is 0.867 and the value of (Cronbach alpha) calculated for reliability study is 0.865 . Findings related to the studies of validity and reliability show that the scale has a valid and reliable form.
\end{abstract}

Keywords: attitude, discussion, attitude scale, pre-service teachers

\section{Extended Abstract}

Purpose and Significance: In this study, developing a scale to measure the attitudes towards the discussion ability of pre-service teachers indented. In order to have an active lesson, students need to express their thoughts. It is important for a student to be active during the lesson, to take the responsibility of his own learning. In traditional teaching, students can't take the responsibility. They feel anxious and the teacher is always considered as an authority in classroom. This feeling effects students' participation. Students most of the time think that it is not true to criticize something during the class or to criticize teacher. And also many teachers feel worried about letting students talk. They don't want to be criticized. They are afraid of losing control of the lesson and losing the power of authority. To prevent this, a teacher needs to use many techniques; one of them is discussion method. In discussion, student is active and can communicate with each other. With the help of dialogues, a student can participate the lesson and take the responsibility of learning.

Methods: In this study the application scale of the discussion ability is developed in the direction of the pre-service teachers. The scale is likert-type comprising of 57 articles. The validity and reliability of the scale is done on the data gained from 200 students elected by the method of coincidental exemplification amount of the sophomore students. As a result of the factorial validity of the scale articles changes between 0.59 and 0.76 and that the KMO Kaiser-Meyer-Olkin value is 0.867 and the value of (Cronbach alpha) calculated for reliability study is 0.865 . And also Barlette

\footnotetext{
${ }^{*}$ Corresponding Author: Assoc. Prof. Dr., Afyon Kocatepe University, Afyonkarahisar, Turkey, gocak@aku.edu.tr

*** Teacher, Cumhuriyet Anadolu High School, Afyonkarahisar, Turkey, gulcinkarakus@ gmail.com
} 
Test of Sphericity is meaningful. In order to have construct validity Exploratory Factor Analysis is done. The aim is to define dimensions and group items according to these dimensions. Findings related to the studies of validity and credibility show that the scale has a valid and reliable form. In this study, developing a scale to measure the attitudes towards the discussion ability of pre-service teachers indented.. Factor analysis is done to describe the structure of relations of variables or respondents. It is important that the difference between two factor loadings must be more than $\% 10$ and their loadings must also be higher than .30 or .40 .To decide the numbers of factors most common three ways are looking at eigen values greater than 1.0., looking at screen plot, and looking at Total Variance Explained. If the scale total variance level is higher than $\% 50$ it can be considered than the scale measures what it intends to measure. At first, testing scale with 57 items is carried out for 200 students. Then 37 items are taken out related to factor analysis 20 items left with 10 positive items and 10 negative items. It is clear that factor loadings of items changes between .59 and .76 .

Results: As a result of factor analysis first factor which is named as awareness consists the $2^{\text {nd }}, 3^{\text {rd }}, 4^{\text {th }}, 6^{\text {th }}, 7^{\text {th }}, 8^{\text {th }}, 9^{\text {th }}, 12^{\text {th }}, 14^{\text {th }}$ items, second factor named as effect consists the $16^{\text {th }}, 18^{\text {th }}, 19^{\text {th }}, 20^{\text {th }}, 21^{\text {st }}, 25^{\text {th }}$ items and third factor named as shyness consists the $36^{\text {th }}, 37^{\text {th }}, 38^{\text {th }}, 49^{\text {th }}, 50^{\text {th }}$ items. The scale is considered as having three dimension and for each dimension item total correlations changes for the first factor, awareness; between .59 and .76 , for the second factor, effect; between .59 and .74 , for the third factor, shyness;.68 and .73. Credibility values for dimensions are for the first factor, awareness .85 , for the second factor, effect .80 , for the third factor, shyness .80 . That means scale is reliable. According to validity and reliability analysis for "Attitude Scale Towards Discussion Ability" has three dimensions and it measures pre-service teachers discussion ability. Total variance explained by the scale is $\% 51$.

Discussion and Conclusions: Body of literature shows that there is no scale that measures discussion ability but some subjects similar to discussion can be considered as the dimension of discussion. The results acquired from the research show similarities such as "Self Reliance Scale" developed by Akin (2007) has factor loadings between .31 and .75 and its Cronbach alpha value is .83 "Assertivenss Scale" developed by Acar and Öğretmen (2007) has factor loadings between .32 and .74 and its Cronbach Alpha value is .87.Cronbach Alpha value for "Effective Speaking Scale" developed by Yildiz and Yavuz (2012) is .92. When the results of the research are examined, it is seen "Attitude Scale towards Discussion Ability" is a valid and reliable scale and it measures students' discussion ability. When the results of the research are compared with the results of other studies, similar results are reached. 


\title{
Öğretmen Adaylarının Tartışma Becerilerine İlişkin Tutum Ölçeği: Bir Ölçek Geliştirme Çalışması
}

\author{
Gürbüz OCAK ${ }^{*}$ \\ Gülçin KARAKUŞ ${ }^{* *}$
}

Makale Gönderme Tarihi: 18 Haziran 2013

Makale Kabul Tarihi: 26 Ağustos 2014

ÖZET: $\mathrm{Bu}$ çalışmada öğretmen adaylarının tartışma becerilerine yönelik tutumlarını ölçmek amacıyla bir ölçek geliştirilmesi amaçlanmıştır. Tartışma becerisine yönelik tutum ölçeği öğretmen adaylarının görüşleri doğrultusunda geliştirilmiştir. Ölçek 57 maddeden oluşan likert tipi bir ölçektir. Ölçeğin geçerlik ve güvenilirlik çalışması 4.sınıf öğretmen adayları arasından tesadüfi örnekleme yöntemiyle seçilen 200 öğrenciden elde edilen veriler üzerinde yapılmıştır. Ölçeğin KMO Kaiser-Meyer-Olkin (Örneklem Oluşturma Uygunluğu Ölçümü) değerinin 0.867 olduğu, yapı geçerliliğini belirlemek amacıyla yapılan faktör analizi sonucunda ölçek maddeleri faktör yüklerinin 0.59 ile 0.76 arasında değiştiği, güvenirlik çalışması için hesaplanan, iç tutarlık katsayı (Cronbach alpha) değerinin 0.865 olduğu görülmüştür. Yapılan faktör analizi sonucuna göre ölçek üç boyutlu olarak yapılandırılmıştır, bu boyutlar; farkındalık, etki ve çekingenlik olarak belirlenmiştir. Geçerlik ve güvenirlik çalışmalarına ilişkin bulgular, ölçeğin geçerli ve güvenilir bir yapıya sahip olduğunu göstermektedir.

Anahtar sözcükler: tutum, tartışma, tutum ölçeği, öğretmen adayları.

\section{Giriş}

Geleneksel eğitimden çağdaş eğitime yönelim sürecinde öğrencinin bireysel koşullarının önemi gün geçtikçe artmaktadır. Bir öğrencinin eğitim sürecinde bilişsel özelliklerinin yanı sıra duyuşsal özellikleri de etkilidir. Duyuşsal özellikler hazırbulunuşluk, ilgi, değer, vb olarak örneklendirilebilir. Bu duyuşsal özelliklerden biri de öğrencinin bir derse, konuya ya da etkinliğe yönelik tutumudur. Wenden (1998), tutumu, öğrenilen motivasyon, değer verilen inanç, bir görüşe doğru yaklaşan ya da o görüşten uzaklaştıran değerlendirmeler olarak tanımlar. Bu tanımdan da anlaşılacağ üzere tutum bireysel bir farklılıktır. Dolayısıyla öğrencilerin olumlu tutum göstermeleri eğitim sürecini de etkilemektedir. Öğrenciler hayat boyu öğrenmeye yönelik olumlu bir tutum geliştirmeleri amacıyla desteklenmeli ve kendileri için öğrenmeleri gerektiği düşüncesi ile yönlendirilmeli (Mok \& Lung, 2005). Ancak, öğrencinin kendi öğreniminin sorumluluğunu alması aynı zamanda duyuşsal özelliklerinden etkilenerek inanç ve davranışlarını yönlendirmesine neden olur. Duyuşsal özellikler hem birbirlerini hem de davranış1 etkilerler. Fishbein ve Ajzen (1975)'e göre inanç, tutum, niyet ve davranış birbirleriyle etkileşim halindedir. Onlar, bu durumu gösteren basit bir model oluştururlar. Modele göre inanç, tutumu, tutum, niyeti ve son olarak niyette davranış1 etkiler. Davranış sonucunda ise inanç tekrar etkilenir. İnancı bilişsel bir süreç olarak, tutumu öğrenilen lehte veya aleyhte meyil olarak tanımlar. Benzer şekilde Ajzen (1988), ayrıca tutuma sosyo-psikolojik açıdan yaklaşır ve tutumu bireyin belli bir davranışı yapmaya yönelik pozitif ya da negatif değerlendirmesi olarak tanımlar ve böylece tutum ve davranış arasındaki bağlantıyı netleştirir. Tutum ve davranış arasındaki ilişkiye Allport (1954) şu şekilde değinmiştir; tutum tecrübe ile oluşan, bireylerin ilgili bütün konularda ve durumlarda tepkisini etkileyen, hazırbulunuşluğun zihinsel ve sinirsel halidir. Gardner (1985) ise tutumu bireyin inanç ve düşüncelerine bağlı olarak verdiği değerlendirici tepki olarak tanımlar. Bu değerlendirici tepkiler Eagley \& Chaiken

\footnotetext{
*Sorumlu Yazar: Doç. Dr., Afyon Kocatepe Üniversitesi, Afyonkarahisar, gocak@aku.edu.tr

** Ögrretmen, Cumhuriyet Anadolu Lisesi, Afyonkarahisar, gulcinkarakus@gmail.com
} 
(1998)'in tanımında belli bir varlığa yönelik lehte veya aleyhte, tutumu etkileyen psikolojik bir eğilim olarak yer alır.

Öğrencinin kendi öğreniminin sorumluluğunu almasında farklı teknik ve stratejilerin kullanılması da önemlidir. Çünkü geleneksel yöntemlerde öğretmen otoritesi hakimdir ve genellikle düz anlatım yöntemi sık kullanılır, oysa artık günümüzde farklı özelliklere sahip öğrencilere hitap edebilecek yöntem ve teknik çeşitliliği oluşturmak gerekir. Bu sayede öğrencinin kendi kendine öğrenmesi de teşvik edilecektir. Farklı yöntemlerden biri de tartışma yöntemidir. Öğretmenler çoğu zaman karşılaştıkları pek çok zorluğa bağlı olarak tartışma yöntemini kullanmaktan kaçınır. Bu zorlukların bazılar şunlardır: öğrencilerin sınıfta sürekli yüksek sesle konuşmaları, öğretmenlerin sınıf hakimiyetini kaybetmeye dair hissettikleri tedirginlik, bu yöntemle konunun içeriğinin öğrenilemeyeceği düşüncesidir (Gall \& Gillet, 1980).Oysa tartışma metodunu kullanan öğretmenler, öğrencilerinin düşünmelerini, bu düşüncelerini savunmalarını istedikleri için bu yöntemi kullandıklarını ve tartışmanın çok yararlı bir strateji olduğunu ifade ederler (Buchanan, 2011).

Tartışma sınıfta öğrencinin derse katılımının artmasını sağlar, öğrenci düşüncesini daha rahat dile getirir ve öğretmenin öğrenmeyi kolaylaştırıcı rolü artar. Elbette tartışma tek başına bir konunun anlaşılmasında yeterli değildir, ancak bu yolda önemli bir adımdır (Murhpy, Soter, Wilkinson, Hennessey \& Alexander, 2009). Tartışma öğrencinin motivasyonunu arttırır ve öğrenme sürecini daha ilgi çekici hale getirir. Ayrıca öğretmen öğrencinin ne öğrendiğini daha derinden anlama firsatı bulur (Cashin, \& Mc Knight,1986).

Tartışma özellikle öğrencinin derse katılımını ve aktif olmasını sağladığı için faydalıdır. Fakat sınıfta tartışma kullanmaya engel olan sınırlayıcılar vardır: sınıfın büyüklüğü, öğrencilerin yeterlilik seviyeleri ve zaman sınırlayıcılarıdır (Green \& Lam,1997). Örneğin, Westcott (1982), yaptığ 1 çalışmada tartışmaları amaciyla öğrencilere çok seçenek sunduğunu ve başlangıçta kargaşa ortamının oluştuğunu belirtmiştir. Bununla birlikte tartışma becerisi yabancı dil eğitiminde ise genellikle nispeten daha yüksek seviyede dil becerisi gerektirdiği için sadece ileri düzeydeki sınıflar için uygun olarak düşünülür. $\mathrm{Bu}$ nedenle pek çok öğretmen tartışmayı uygulamaz, denemez ya da olumsuz tecrübeler nedeniyle tartışmadan vazgeçebilmektedir. Öğrenci merkezli yaklaşımın mantığını destekleyen öğrenen özerkliğinin gelişimi için tartışma becerisinin geliştirilmesi öğrencinin son derece özgür olması, kendi öğrenimini yönlendirmesi için gereklidir (Green \& Lam, 1997).

Henning'e (2008) göre anlatım ile tartışma arasındaki benzerlik ve farklılıkları şu şekilde sıralayabiliriz; anlatım ile karşılaştırıldığı zaman tartışma sınıfta konuşmaktan farklı fakat ona bağlı bir yöntemdir. Konuşma çok geniş kapsamlıdır ve öğretmen ve öğrenci arasındaki her türlü sözel iletişimi kapsar. Düz anlatım, monolog ve tek yönlü iletişimden farklı olarak tartışmada ve anlatımda öğrenci bir diyaloğa dahil olur ve öğrenci ile öğretmen arasında iki yönlü iletişim vardır. Anlatımda diyalog basittir. Öğretmen soru sorar, öğrenci cevaplar. Buna karşın tartışma da bir nevi anlatım içerir ancak çok daha karışık bir süreçtir. Tartışmayı sürdürmek için öğretmen açık uçlu daha uzun cevaplar gerektiren sorular sorar. Tartışma ile eğitim program hedeflerine daha sistematik olarak ulaşılır, sosyal iletişim ve öğrencinin düşünmesini sağlanır.

Hadjioannou (2007)'nin incelediği çalışmalarda (bkz. Rosenblatt, 1995; Langer, 1995; Gambrell, 1996; Wells, 2000) edebi tartışmaların öğrencinin anlama becerisini önemli oranda geliştirdiğini belirtilir. Ayrıca literatürde yapılan çalışmalarda sınıf etkileşiminde diyalog kurmanın eleştirel düşünmeyi geliştirdiği (Applebee, 2002; 
Gambrell, 1996), öğrencilerin iletişim becerilerini olumlu yönde etkilediği (Almasi, 1996) ve sınıf üyeleri açısından kişiler arası ilişkilerde olumlu etki oluşturduğu (Langer, 1995; Slavin, 1990) ve öğrencileri demokratik toplum hayatına ve bu sürece hazırlamaya yardım ettiği ifade edilmektedir.

Howell (2008), yaptığı çalışmada işbirlikçi araştırma çalışması esnasında tartışma yöntemi kullanmanın öğrenci katılımını \%8 arttırdığını ve öğrencinin veri analizi yapabilme becerisinin ilerleme gösterdiğini ifade edilmektedir. Özellikle en düşük seviyedeki öğrencilerin daha fazla ilerleme gösterdiği, yüksek seviyedekilerin veri analizinde fazla ilerlemediği belirlenmiştir.

Bütün bu olumlu etkileri göz önüne alındığında bir öğretmenin de tartışma becerisine sahip olması gerektiği açıktır. Mok \& Lung (2005) tarafından, öğretmen adaylarının güçlü motivasyona ve olumlu tutma sahip olduklarına dair olumlu bir kanıt bulunmadığı, ayrıca öğretmen adaylarının öz yeterlilik inancı ve gelişmiş bağımsız, sistematik bir araştırma başlatabilecek algılarına yönelik kanıtlardan yoksun oldukları ifade edilir. Öğretmenler tartışmaya dair bazı önyargılara sahip oldukları için sınıf ortamında tartışmaktan kaçınmaktadır. Bu durum öğrencilerin eleştirel düşünme becerilerinin gelişmemesine neden olmaktadır. Oysa tartışabilmek, sorgulayabilmek, kendi fikrini dile getirebilmek ve bu fikri savunabilmek öğrencinin eğitim hayatında önemli bir yere sahiptir. Bu nedenle öğretmen adaylarının tartışmaya dair tutumlarının tespit edilmesi gerekir. Öğretmen adaylarının tartışma becerilerindeki eksiklik giderilirse onlar da öğrencilerine tartışabilecekleri ortamlar sunar. $\mathrm{Bu}$ sayede öğrencilerin bakış açıları değişebilir. Öğretmen adayı mesleğine başladığı zaman iyi bir tartışma ortamı düzenlemeye ve onu yönetmeye yönelik becerilere sahip olmalıdır. Bu bağlamda mesleğe henüz başlamamış öğretmen adaylarının tartışmaya yönelik bakış açılarının incelenmesi oldukça önemlidir. Literatürde bu alanda yapılmış bir çalışmaya rastlanmamıştır. $\mathrm{Bu}$ çalışmada öğretmen adaylarının tartışma becerilerine yönelik tutumlarını ölçmek amacıyla bir ölçek geliştirilmesi amaçlanmıştır.

\section{Yöntem}

$\mathrm{Bu}$ bölümde araştırmanın çalışma grubu, ölçme aracının geliştirilmesi ve verilerin analizinde kullanılan tekniklere değinilmiştir.

\section{Araştırma (Çalışma) Modeli}

Öğretmen adaylarının tartışma becerisine yönelik tutumlarını ölçmede kullanılabilecek bir ölçek geliştirmeyi amaçlayan bu araştırmada tarama modeli kullanılmıştır, tarama modelleri, geçmişte ya da halen var olan bir durumu var olduğu şekliyle betimlemeyi amaçlayan araştırma yaklaşımıdır. Araştırmaya konu olan olay, birey ya da nesne, kendi koşulları içinde ve olduğu gibi tanımlanmaya çalışılır (Karasar, 2006).

\section{Çalışma Grubu}

Araştırmanın çalışma grubu, 2012-2013 akademik y1lı Ege bölgesindeki bir üniversitenin Eğitim Fakültesi Sosyal Bilgiler Öğretmenliği Bölümü son sınıfta öğrenim 
görmekte olan 62 erkek (\% 31) ve 138 kı (\% 69) öğretmen adayından oluşmaktadır. Tartışma becerisine yönelik tutumların son sınıflarda daha net belirginleşeceği düşüncesiyle çalışma grubu olarak son sınıf öğrencilerinin araştırma kapsamına alınması uygun görülmüştür. Ölçek geliştirme çalışmalarında örneklem büyüklüğü için farklı görüşler bulunmaktadır. Örneğin Kline (1994), örneklemin ölçekteki madde sayısının en az iki en çok on katı olabileceğini ifade ederken Tavşancıl (2010) ve Tekindal (2009) ise örneklem büyüklügüüün madde sayısının üç ile beş kat olabileceğini belirtmektedir. Bu bağlamda bu çalışmada madde sayısının dört katı civarında örneklem sayısı göz önüne alınmıştır.

\section{Ölçme Aracının Geliştirilmesi}

En popüler tutum ölçeği türü olan Likert tipi ölçekte bir ifadeyi farklı seviyelerde onay takip eder; kesinlikle katılıyorum, katılıyorum, kararsızım, katılmıyorum, kesinlikle katılmıyorum gibi ve beş aşamalı ölçüm kullanılır. Likert tipi ölçek bir araştırmacı için son derece kullanışlı bir ölçme aracıdır çünkü hassasiyeti ve farklılığın derecesini belirtir ve özellikle fikirleri ve tutumları ölçmede sıklıkla kullanılır (Yount, 2006).

Likert tipi ölçek cevaplayıcının cevabını duyuşsal bağlamda pozitif ile negatif arasında bir yere yerleştirir, değerlendirilen performansı derecesine göre sıralar (Dorn, Madeja \& Sobal, 2004). Likert tipi ölçekte alınan toplam puan, maddelere gösterilen tepkilere verilen ağırlıkların (madde puanların) toplamından oluşmaktadır. Cevaplayıcı ölçekte bulunan maddelerin her birine tepkide bulunurken, bu maddenin kapsamına ilişkin tutumun derecesini bildirdiği varsayılır. Tüm psikolojik ölçeklerin bazı temel sayıltıları vardır. Bunlar süreklilik, tek boyutluluk ve doğrusallıktır. Süreklilik sayıltısında ölçülen özelliğin sonsuza kadar küçülebilen birimlerle ölçülebilen bir değişken olduğu kabul edilir. Tek boyutluluk sayıltısı, ölçülen bir özelliğin tek başına tanımlanabileceği ve ölçülebileceği anlamına gelir. Doğrusallık sayıltısında ise, ölçülen özelliğin ölçülerinin bir doğru üzerinde gösterilebileceği kabul edilir. Bu sayıltılar Likert tipi tutum ölçekleri için de geçerlidir (Tezbaşaran, 1996). Anderson'a göre (1981), Likert tipi tutum ölçeği hazırlanırken izlenmesi gereken adımlar şunlardır: ölçülmek istenen tutuma ilişkin olumlu ve olumsuz maddeler yazılır, uzmanlardan her bir maddeyi incelemeleri istenir, uzmanlar tarafindan uygun görülmeyen maddeler ölçekten çıkartılır, geriye kalan maddeler seçkisiz olarak sıralanır. Uygun yönerge ve tepki seçenekleri eklenir, böylece ölçeğin ilk formu uygulamaya hazırlanmış olur, ölçeğin uygulanacağı örneklem belirlenir ve belirlenen gruba uygulanır, uygulama yapılan her birey için madde puanı ve madde puanları toplamından oluşan toplam ölçek puanı hesaplanır, her bir madde ile toplam ölçek puanı arasında korelasyon hesaplanır, istatistiksel olarak anlamlı olmayan korelasyon katsayısına sahip olan maddeler ölçekten atılır. Her maddenin, tüm maddeler ile ilişkisi olması gereği likert ölçeğinin iç tutarlık ölçütüdür. Likert tipi tutum ölçeği hazırlamak için bir seri işlemin gerçekleşmesi gerekmektedir. $\mathrm{Bu}$ işlemler, araştırmaya konu olan ölçek kapsamında aşağıda sıralanmaktadır. 
Öğretmen adaylarının tartışma becerisine yönelik tutumlarını ölçmeye yönelik aracın geliştirilmesinde ilk aşamada konuyla ilgili kaynaklar gözden geçirilmiştir (Gall\& Gillet, 1980;Cashin \&Mc Knight, 1986; Buchanan,2011) ancak bu amaçla hazırlanan herhangi bir ölçeğe rastlanmamıştır. Daha sonra ölçeğin uygulanacağ bireyler göz önüne alınarak öğretmen adaylarına tartışma ile ilgili açık uçlu sorular yöneltilmiştir. Bu sorular: Dersle ilgili öğretmeninizle tartışmaktan neden çekinirsiniz? Eğer tartışma konunuzda haklıysanız ne yaparsınız? Dersle ilgili tartışmaktan hoşlanır mısınız? Derste öğretmenle ve sınıfla tartışma yapmak size neler katar? Elde edilen cevaplar analiz edilerek tartışmaya yönelik tutumları ifade eden ve önceden tasarlanan anahtar kavramlar çerçevesinde maddeler oluşturulmuştur. $\mathrm{Bu}$ anahtar kavramlar çerçevesinde ölçek planı yapılmıştır ve ölçek maddeleri belirlenmiştir.

Anahtar kavramlar tartışmaya yönelik olumlu ya da olumsuz tutum ifadeleri içeren ve tartışmanın etkisini ifade eden kavramlardan oluşmaktadır(Cashin \& Mc Knight, 1986). Belirlenen olumlu ve olumsuz tutum maddeleri 5'li Likert şeklinde "kesinlikle katılıyorum", "katıllyorum", "kararsızım", "katılmıyorum", "kesinlikle katılmıyorum" şeklinde derecelendirilmiştir. Böylece öğretmen adaylarının tartışmaya yönelik tutumlarını ifade edebilecek 77 tane madde yazılmıştır. Bu maddelerden 23 tanesi olumsuz madde niteliğindedir.

Daha sonra hazırlanan ölçek maddelerin kapsam geçerliliği sağlamak için uzman görüşüne sunulmuştur. Görüşü alınan uzmanlar iki öğretim görevlisi, iki Türkçe öğretmeni ve bir dil uzmanından oluşmaktadır. Uzman görüşlerinden elde edilen dönütlere göre cümlelerde dilbilgisi kapsamında gerekli düzeltmeler yapıldı. Ayrıca farklı şekillerde anlaşılabilecek ifadeler yine uzman görüşleri doğrultusunda düzeltildi. Daha sonra, ölçek 25 kişilik son sınıflardan oluşan öğrenci grubuna uygulanarak dil ve anlatım yönünden problem olup olmadığı tespit edilip; gerekli düzeltmeler yapılarak ölçeğe son şekli verilmiştir. Bu düzeltmeler doğrultusunda anlaşılmadığı belirlenen 20 madde ölçekten çıkarılmıştır ve geriye kalan 57 madde ölçekte yer almıştır. Son sınıfta okuyan öğretmen adayları aldıkları Özel Öğretim Yöntemleri ya da benzeri dersler sayesinde sınıfta tartışabilme ya da bir tartışma başlatabilme gibi özelliklere daha yatkın oldukları için son sınıflar seçilmiştir. Gerekli düzenlemelerden sonra 57 maddelik deneme ölçeği Eğitim Fakültesi son sınıfta öğrenim gören (62 erkek öğrenciye, 138 kız öğrenciye/) toplam 200 öğrenciye uygulanmıştır.

Tartışmaya Yönelik Tutum Ölçeğinin geliştirilmesine ilişkin uygulama sonucunda elde edilen veriler bilgisayar ortamına aktarılmıştır. Araştırmacı tarafından öğrencilerin tutumlarını ölçmeye yönelik 57 maddelik 5 dereceli Likert tipi bir tutum ölçeği formu hazırlanmıştır. Böylece ölçeği cevaplayan her bir öğrenci her bir maddeye beşli dereceleme boyutunda tepkide bulunmaktadır. Bunlar; 'kesinlikle katılıyorum, katıliyorum, kararsızım, katılmıyorum, kesinlikle katılmıyorum' şeklindedir. Denemeye tabi tutulan tutum maddeleri puanlandıktan sonra, iyi işlemeyen maddeleri seçmek için madde analizi yapılmışıtır. 


\section{Bulgular}

Ölçeğin yapı geçerliliğini belirlemek için faktör analizi türlerinden açımlayıcı faktör analizi yapılmıştır. Açımlayıcı faktör analizi (Exploratory Factor Analysis) sosyal bilimlerde sıkça kullanılan bir istatistiksel tekniktir. Süreç birkaç belirgin ilkeyi ve pek çok seçeneği kapsayan bir yapıya sahiptir (Costello \& Osborne, 2005). Costello ve Osborne (2005) yaptıkları araştırmalarda açımlayıcı faktör analizinin çok çeşitli ölçme aracı geliştirme uygulamalarında (Lovett, Zeiss, \& Heinemann, 2002),öğrenci motivasyonlarını değerlendirmede (Morris, 2001) kullanıldığını belirlemişlerdir.

Faktör analizi ölçümlerde varyasyon ve ilişkili varyasyonu istatistiksel olarak açıklayan faktörleri belirlemede kullanılan bir tekniktir. Genellikle faktör sayısı ölçümlerden azdır ve sonuçtaki faktörler ölçümleri temsil eder. Bu açıdan ele alındığında faktör analizi, üst üste çakışan çok sayıda ölçümü daha küçük faktöre indirgediği için bir veri azaltma tekniği olarak da algılanabilir. Eğer bir araştırma iyi planlandıysa farklı ölçüm grupları farklı boyutları yansıtır ve faktör analizi bu boyutların ortaya çıkmasını sağlar. Daha belirgin olarak faktörler ölçme aracının yapılarına uyum sağlar. Bu da bizim davranışı anlamamızı sağlar. Faktör analizi sonuçları bizim ölçek maddesi seçimimize ve araştırmaya katılanların cevaplarına bağlıdır (Green \& Salkind, 2005).

Ölçek geliştirme ile ilgili literatürde faktörlerin oluştururken 0.30 ile 0.40 arasında değișen faktör yüklerinin alt kesme noktası olarak alınabileceği belirtilmektedir (Marsh \& Yeung, 1999).Bu nedenle faktör yüklerinin alt kesme noktası olarak 0.40 değeri esas alınmıştır. Bir maddenin faktörlerdeki en yüksek yük değeri ile bu değerden sonra en yüksek olan yük değeri arasındaki farkın olabildiğince yüksek olması beklenir. Yüksek iki yük değeri arasındaki farkın en az.10 olması önerilir(Cureton \& D’Agostino, 1983).

Araştırmadan elde edilen verilerin faktör analizine uygunluğunu belirlemek için yapılan ön analizler sonucunda; KMO Kaiser-Meyer-Olkin (Örneklem Oluşturma Uygunluğu Ölçümü) değeri .867 ve Barlett testi (Bartlett Bütünlük Testi) sonucu anlamlı $(p=.00$ olarak bulunmuştur $(p<.05)$. Bulunan bu değerler verilerin faktör analizine uygunluğunun bir göstergesi olarak kabul edilebilir. KMO (Kaiser-Meyer-Olkin) (Örneklem Oluşturma Uygunluğu Ölçümü) gözlenen korelasyon katsayıları büyüklügü ile kısmı korelasyon katsayılarının büyüklüğü karşılaştıran bir indekstir. KMO oranının (0.5)'in üzerinde olması gerekir. Oran ne kadar yüksek olursa veri seti faktör analizi yapmak için o kadar iyidir denilebilir (Sharma,1996:Akt, Kalayc1, 2006). Barlette testi (Barlett test of Sphericity) korelasyon matrisinde değişkenlerin en azından bir kısmı arasında yüksek oranlı korelasyonlar olduğu olasılığını test eder. Analize devam edilebilmesi için "Korelasyon matrisi birim matrisidir" sıfir hipotezinin reddedilmesi gerekir. Eğer sıfır hipotezi reddedilirse, değişkenler arasında yüksek korelasyonlar olduğunu, başka bir ifadeyle veri setinin faktör analizi için uygun olduğunu gösterir (Hair v.d.1998: Akt, Kalayc1, 2006).

Faktör analizi ile 57 maddeden oluşan “Tartışmaya Yönelik Tutum Ölçeği”nin tek ya da çok faktörlü olup olmadığı saptanmaya çalışılmıştır. 57 madde ile faktör 
analizine başlanmış olup toplam 16 faktör elde edilmiştir ve bulunan 16 faktör toplam varyansın \% 64'ünü açıklamaktadır. Yapılan faktör analizleri sonucunda 37 tane madde ölçekten çıkarılmıştır. Faktör analizi sırasında 4., 5., 10., 11., 13., 15., 17., 22., 23., 24., 25., 26., 27., 28., 29., 30., 32., 33., 34., 39., 40., 41., 42., 43., 44., 45., 46., 47., 48., 51., 52., 53., 54., 55., 56. maddelerin matrix değerleri arasındaki farkın 0.10 'dan az olduğu fark edilmiş ve ölçekten çıkartılmasına karar verilmiştir. Ayrıca 1., 31., 35., 57.maddelerin değerlerine bakıldığında 0.40 'ın altında olduğu görülmüş ve ölçekten çıkartılmalarına karar verilmiştir. Ancak faktör sayısının fazla olması nedeniyle faktör sayısını belirlemek için Scree plot'a (çizgi grafiği) kullanılmıştır. Faktör sayısı belirlemede genellikle iki istatistiksel teknik kullanılmaktadır. Bunlardan biri özdeğer diğeri ise scree plot grafiğidir (Green \& Salkind, 2005). Faktör sayısını belirlemek için bakılan scree plot grafiğinde 3 ana kırılma noktasının olduğu bu kırılma noktasından sonra eğimin kaybolmaya başladığı görülmektedir. Grafikte eğimin kaybolmaya başladığı noktanın işaret ettiği bileşen sayısı hesaplanacak faktör sayısı olarak alınır. Ana kırılma noktalarına bağlı olarak ölçek 3 faktörle sınırlandırılmıştır.

Şekil 1. Tartışmaya Yönelik Tutum Ölçeğinin Scree plot (Çizgi grafiği / Yamaç Eğim Testi) Grafiğini Gösteren Tablo

\section{Scree Plot}

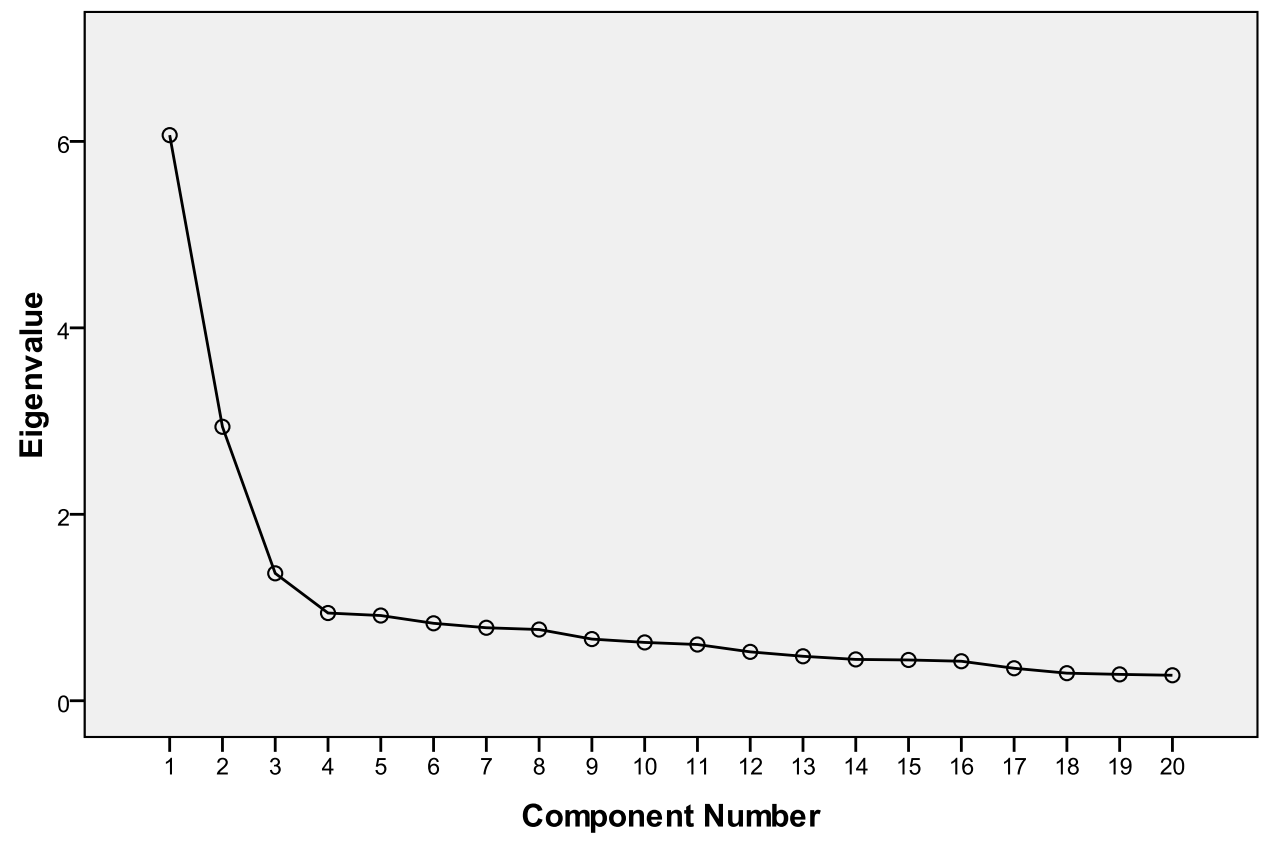

Faktör analizleri sonucunda KMO Kaiser-Meyer-Olkin (Örneklem Oluşturma Uygunluğu Ölçümü) değeri. 867'ye düşmüş olup 3 faktör toplam varyansın \%51.84'ünü açıklamaktadır. KMO (Kaiser-Meyer-Olkin değeri Oluşturma Uygunluğu Ölçümü) .867 bulunmuş ve eigen değeri (Başlangıç Özdeğeri) 1.00'den büyük olan maddeler ölçeğe alınmıştır. Elde edilen değerler faktör analizinin uygulanabileceğinin göstergesi olarak kabul edilmiştir (Cureton \& D’Agostino,1983). Tartışmaya Yönelik Tutum Ölçeğinin Total faktör analizine ilişkin açıklanan varyans değerleri Tablo 1'de verilmiştir. 
Tablo 1

Tartışmaya Yönelik Tutum Ölçeğinin Total Variance Explained (Toplam Varyansın Açıklanması) Tablosu

\begin{tabular}{|c|c|c|c|c|c|c|c|c|c|}
\hline \multirow{2}{*}{$\begin{array}{l}\text { Component } \\
\text { (Madde) }\end{array}$} & \multicolumn{3}{|c|}{$\begin{array}{c}\text { Initial Eigenvalues } \\
\text { (Başlangıç Özdeğerleri) }\end{array}$} & \multicolumn{3}{|c|}{$\begin{array}{l}\text { Extraction Sums of Squared } \\
\text { Loadings } \\
\text { (Karesi Alınan Yüklerin } \\
\text { Toplam Çıkarımı) }\end{array}$} & \multicolumn{3}{|c|}{$\begin{array}{l}\text { Rotation Sums of Squared } \\
\text { Loadings(Karesi Alınan } \\
\text { Yüklerin Döndürme Toplamı) }\end{array}$} \\
\hline & $\begin{array}{l}\text { Total } \\
\text { (Top.) }\end{array}$ & $\begin{array}{c}\% \text { of } \\
\text { Variance } \\
\text { (Varyans) }\end{array}$ & $\begin{array}{l}\text { Cumulative } \\
\text { (Birikimli) }\end{array}$ & $\begin{array}{l}\text { Total } \\
\text { (Top.) }\end{array}$ & $\begin{array}{c}\% \text { of } \\
\text { Variance } \\
\text { (Varyans) }\end{array}$ & $\begin{array}{l}\text { Cumulative } \\
\text { (Birikimli) }\end{array}$ & $\begin{array}{l}\text { Total } \\
\text { (Top.) }\end{array}$ & $\begin{array}{c}\% \text { of } \\
\text { Variance } \\
\text { (Varyans) }\end{array}$ & $\begin{array}{l}\text { Cumulative } \\
\text { (Birikimli) }\end{array}$ \\
\hline 1 & 6.067 & 30.337 & 30.337 & 6.067 & 30.337 & 30.337 & 4.294 & 21.470 & 21.470 \\
\hline 2 & 2.939 & 14.694 & 45.031 & 2.939 & 14.694 & 45.031 & 3.116 & 15.578 & 37.049 \\
\hline 3 & 1.367 & 6.834 & 51.864 & 1.367 & 6.834 & 51.864 & 2.963 & 14.816 & 51.864 \\
\hline 4 & .941 & 4.704 & 56.569 & & & & & & \\
\hline 5 & .914 & 4.570 & 61.139 & & & & & & \\
\hline 6 & .831 & 4.153 & 65.292 & & & & & & \\
\hline 7 & .783 & 3.915 & 69.207 & & & & & & \\
\hline 8 & .764 & 3.819 & 73.026 & & & & & & \\
\hline 9 & .661 & 3.307 & 76.332 & & & & & & \\
\hline 10 & .626 & 3.128 & 79.460 & & & & & & \\
\hline 11 & .603 & 3.015 & 82.475 & & & & & & \\
\hline 12 & .524 & 2.621 & 85.096 & & & & & & \\
\hline 13 & .477 & 2.384 & 87.480 & & & & & & \\
\hline 14 & .443 & 2.216 & 89.696 & & & & & & \\
\hline 15 & .437 & 2.187 & 91.883 & & & & & & \\
\hline 16 & .424 & 2.118 & 94.001 & & & & & & \\
\hline 17 & .348 & 1.742 & 95.742 & & & & & & \\
\hline 18 & .296 & 1.478 & 97.221 & & & & & & \\
\hline 19 & .283 & 1.414 & 98.634 & & & & & & \\
\hline 20 & .273 & 1.366 & 100.000 & & & & & & \\
\hline
\end{tabular}

Tablo 2'de de görüldügü gibi, Rotated Companent Matrix (Döndürülmüş Bileşenler Matriksi) 1.faktörde 9 maddenin, 2. faktörde 6 maddenin, 3. faktörde 5 
maddenin bulunduğu tespit edilmiştir. Ayrıca toplam varyansın açıkladığı oranın yüksek olması beklenmektedir (Gams, Meyers \& Guarino, 2008). \%51 olarak belirlenen bu oran yeterli görülmektedir (Erefe, 2002).

Tablo 2

Rotated Component Matrix ${ }^{a}$ (Dönüştürülmüş Bileşenler Matrisi)

\begin{tabular}{|c|c|c|c|}
\hline & & ompone & \\
\hline & 1 & 2 & 3 \\
\hline s2 & .632 & & \\
\hline s3 & .599 & & \\
\hline s4 & .671 & & \\
\hline s6 & .736 & & \\
\hline s7 & .760 & & \\
\hline s8 & .707 & & \\
\hline s9 & .699 & & \\
\hline $\mathrm{s} 12$ & .629 & & \\
\hline s14 & .621 & & \\
\hline s16 & & .601 & \\
\hline s18 & & .634 & \\
\hline s19 & & .753 & \\
\hline $\mathrm{s} 20$ & & .719 & \\
\hline s21 & & .748 & \\
\hline $\mathrm{s} 25$ & & .592 & \\
\hline s36 & & & .680 \\
\hline s37 & & & -.731 \\
\hline s38 & & & .680 \\
\hline $\mathrm{s} 49$ & & & .733 \\
\hline s50 & & & .724 \\
\hline
\end{tabular}

Ölçeği'in madde analizi t testi kullanılarak üst \%27 ile alt \%27'lik grupların madde ortalamaları arasındaki farkların anlamlılığıyla incelenmiştir. Tutum ölçekleri için madde analizi yapılmasının amacı 'hangi maddelerden oluşturulacak ölçeğin 
güvenirliği ve geçerliği daha yüksek olur' sorusuna cevap aramaktır (Tezbaşaran, 1997). Taslak ölçekten elde edilen verilere değişik madde analizleri uygulayarak, her maddenin nihai ölçeğe alınıp alınmayacağına karar verilebilir (Tezbaşaran, 1997). Uç grupların bir maddeye verdikleri doğru cevap doğru yönde manidar farklılık gösterdiği için ölçekten madde atılmamasına karar verilmiştir.

Yapılan analizler sonucunda ölçeğin üç faktörlü çıktığı, bu durumun tartışma becerisine yönelik üç temel yapıyı (farkındalık, etki, çekingenlik) yansıttığı düşünülmüştür.

Farkındalık faktöründe yer alan maddeler tartışmanın olumlu sonuçlarına yönelik bilinci ifade ettiği için farkındalık olarak adlandırılmıştır.

Etki faktöründe yer alan maddeler ise tartışmanın sinıftaki etkisini ifade etmektedir.

Çekingenlik boyutundaki maddeler ise öğrencilerin tartışmaktan kaçınmalarını çekinmelerini ifade etmektedir.

Tüm kriterler göz önünde bulundurularak yapılan değerlendirme sonucunda 57 maddelik deneme ölçeğinin 37 maddesi ölçekten çıkarılmış bu durumda ölçekte 10'u olumsuz 10'u olumlu olmak üzere 20 madde kalmıştır. Yapılan analiz sonucunda faktör yük değerlerinin, üç faktör için de .59 ile .76 arasında yüksek düzeyde değiştiği görülmektedir. Üç faktörlü olarak saptanan ölçeğin her bir alt faktör için madde toplam korelasyonları I. Faktör için . 59 ile .76; II. Faktör için .59 ile .74; III. Faktör için .68 ile .73 arasında değişmektedir. Buna göre her bir maddenin katılımcıların tartışmaya yönelik tutumlarını iyi ayırt ettiği söylenebilir.

Tartışmaya Yönelik Tutum Ölçeğinin "Farkındalık" alt boyutuna ait geçerlikgüvenirlik analizi sonuçları Tablo 3 'te verilmiştir. Tablo 3 incelendiğinde birinci faktörde yer alan maddelerin tartışmanın olumlu etkilerinin fark edilmesine yönelik maddeler olduğu anlaşılmıştır ve bu nedenle bu faktör "farkındalık" olarak adlandırılmıştır. Farkındalık faktöründe yer alan maddelerin faktör yük değerlerinin .59 ile .76 arasında değiştiği görülmektedir. 


\section{Tablo 3}

Tartışmaya Yönelik Tutum Ölçeğinin Farkındalık Alt Boyutuna Ait Geçerlik-Güvenirlik Analizi Sonuçları

\begin{tabular}{|c|c|c|c|c|c|c|c|c|}
\hline $\begin{array}{l}\text { Madde ve Faktörler } \\
\text { I.FAKTÖR (Farkındalık) }\end{array}$ & 5 & $\tilde{n}$ & 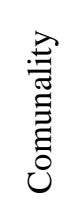 & 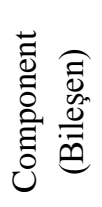 & 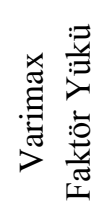 & 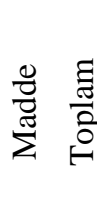 & $\mathrm{t}$ & $\mathrm{p}$ \\
\hline $\begin{array}{l}\text { 2.Tartışma yöntemi farklı görüşlere } \\
\text { tahammül edebilmeyi sağlar. }\end{array}$ & 4.39 & 0.81 & .421 & .518 & .632 & 41 & 4.95 & .001 \\
\hline $\begin{array}{l}\text { 3.Öğretmenle tartışırken kendi hakkımı } \\
\text { savunmak hoşuma gider. }\end{array}$ & 4.23 & 0.90 & .439 & .560 & .599 & 47 & 6.36 & .000 \\
\hline $\begin{array}{l}\text { 4.Öğretmenle tartışmak kendimi etkili ve } \\
\text { doğru ifade edebilmemi sağlar }\end{array}$ & 4.11 & 0.93 & .475 & .560 & 671 & 46 & 6.24 & .000 \\
\hline $\begin{array}{l}\text { 6.Ö ğretmenle tartışmak } \quad \text { doğru } \\
\text { bildiklerimin kalıcılığını arttırır. }\end{array}$ & 4.16 & 0.92 & .549 & .536 & .736 & 43 & 5.83 & .000 \\
\hline $\begin{array}{l}\text { 7.Öğretmenle tartışmak eksik bilgilerimi } \\
\text { tamamlamamı sağlar. }\end{array}$ & 4.19 & 0.91 & .611 & 639 & .760 & 54 & 7.21 & .000 \\
\hline 8.Tartışma bana deneyim kazandırır. & 4.28 & 0.76 & .540 & .559 & .707 & 45 & 5.92 & .117 \\
\hline $\begin{array}{l}\text { 12.Öğretmenle tartışmak farklı fikirlerin } \\
\text { ortaya çıkmasını sağlar }\end{array}$ & 4.19 & 0.94 & .517 & .583 & 699 & 47 & 4.82 & .129 \\
\hline $\begin{array}{l}\text { 14.Öğretmenle tartışmam sınıfta } \\
\text { demokrasi olduğunu gösterir. }\end{array}$ & 4.23 & 0.87 & .411 & .474 & .629 & 34 & 4.55 & .005 \\
\hline 9.Tartışma dersi sıkıcılıktan kurtarır. & 4.19 & 0.97 & .394 & .480 & 621 & 38 & 5.93 & .000 \\
\hline
\end{tabular}

Tartışmaya Yönelik Tutum Ölçeğinin "Etki" alt boyutuna ait geçerlik-güvenirlik analizi sonuçları Tablo 4'te verilmiştir. Tablo 4 incelendiğinde ikinci faktörde yer alan maddelerin sınıf ortamında tartışmanın ne gibi etkileri olacağına dair ifadeler içerdiği görülmektedir ve bu nedenle bu faktör “ etki” olarak adlandırılmıştır.Etki faktöründe yer alan maddelerin faktör yüklerinin . 59 ile .75 arasında değiştiği görülmektedir. 
Tablo 4

Tartışmaya Yönelik Tutum Ölçeğinin Etki Alt Boyutuna Ait Geçerlik-Güvenirlik Analizi Sonuçları

\begin{tabular}{|c|c|c|c|c|c|c|c|c|}
\hline $\begin{array}{l}\text { Madde ve Faktörler } \\
\text { II.FAKTÖR (Etki) }\end{array}$ & 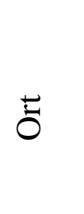 & $\tilde{s}$ & 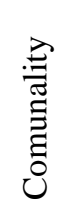 & 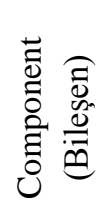 & 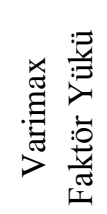 & 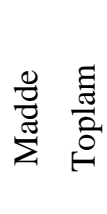 & $\mathrm{t}$ & $\mathrm{p}$ \\
\hline $\begin{array}{l}\text { 16.Öğretmenle tartışmam } \\
\text { aramızdaki olumlu ilişkiyi } \\
\text { zedeler. }\end{array}$ & 3.51 & 1.29 & .492 & .621 & .601 & 56 & 8.88 & .024 \\
\hline $\begin{array}{l}\text { 18.Tartışma yöntemi bana } \\
\text { tartışma sanatını öğretmez. }\end{array}$ & 3.59 & 1.19 & .487 & .581 & .634 & 52 & 8.31 & .000 \\
\hline $\begin{array}{l}\text { 19.Öğretmenle tartışırsam } \\
\text { konudağılır. }\end{array}$ & 3.71 & 1.18 & .664 & .677 & .753 & 62 & 10.0 & .000 \\
\hline $\begin{array}{l}\text { 20.Öğretmenimle tartışırsam } \\
\text { ona saygısızlık olur. }\end{array}$ & 3.88 & 1.15 & .574 & .596 & .719 & 54 & 8.88 & .000 \\
\hline $\begin{array}{l}\text { 21.Öğretmenimle } \\
\text { gergin sartışırsam } \\
\text { hoşlanmam. }\end{array}$ & 3.32 & 1.31 & .575 & .496 & .748 & 46 & 9.10 & .555 \\
\hline $\begin{array}{l}\text { 25.Öğretmenle tartışarak } \\
\text { dikkati üzerime çekmekten } \\
\text { hoşlanmam. }\end{array}$ & 3.08 & 1.37 & .420 & .475 & .592 & 43 & 9.17 & .000 \\
\hline
\end{tabular}

Tartışmaya Yönelik Tutum Ölçeğinin "Çekingenlik" alt boyutuna ait geçerlikgüvenirlik analizi sonuçları Tablo 5 'te verilmiştir. Tablo 5 incelendiğinde üçüncü faktörde yer alan maddelerin sınıf ortamında tartışmaya katılmaktan çekinmeye dair ifadeler içerdiği görülmektedir ve bu nedenle bu faktör " çekingenlik" olarak adlandırılmıştır. Etki faktöründe yer alan maddelerin faktör yüklerinin . 59 ile .75 arasında değiştiği görülmektedir. 


\section{Tablo 5}

Tartışmaya Yönelik Tutum Ölçeğinin Çekingenlik Alt Boyutuna Ait GeçerlikGüvenirlik Analizi Sonuçları

\begin{tabular}{|c|c|c|c|c|c|c|c|c|}
\hline $\begin{array}{l}\text { Madde ve Faktörler } \\
\text { III.FAKTÖR (Çekingenlik) }\end{array}$ & 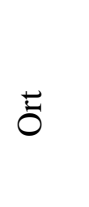 & $\approx$ & 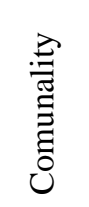 & 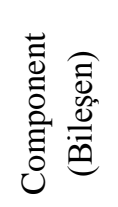 & 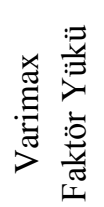 & 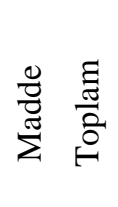 & $\mathrm{t}$ & $\mathrm{p}$ \\
\hline 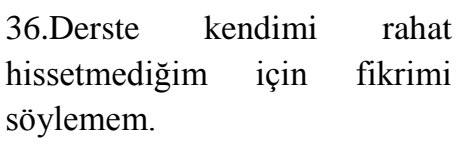 & 2.91 & 1.38 & .511 & .503 & .680 & 45 & 9.23 & .000 \\
\hline $\begin{array}{l}\text { 37.Öğretmenle tartısmam } \\
\text { çünkü o her zaman haklıdır. }\end{array}$ & 1.98 & 1.27 & .592 & .541 & .731 & 50 & 6.35 & .000 \\
\hline 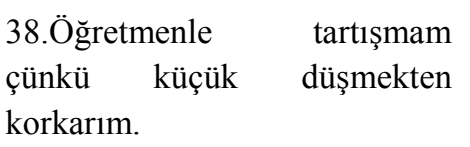 & 3.70 & 1.28 & .555 & .551 & .680 & 48 & 9.58 & .000 \\
\hline $\begin{array}{l}\text { 49.Kendimi bir konu hakkında } \\
\text { öğretmenle tartışabilecek kadar } \\
\text { yeterli görmüyorum. }\end{array}$ & 3.64 & 1.21 & .585 & .528 & .733 & 47 & 9.98 & .000 \\
\hline $\begin{array}{l}\text { 50.Öğretmenden farklı } \\
\text { düşünürsem bu görüşümü ifade } \\
\text { etmem. }\end{array}$ & 3.61 & 1.20 & .562 & .528 & .724 & 46 & 8.09 & .000 \\
\hline
\end{tabular}

Tartışmaya Yönelik Tutum Ölçeğinin alt faktörlerinin açıkladığı variyans oranları ve alfa katsayılarına ilişkin sonuçlar Tablo 6'da verilmiştir.

Tablo 6

Tartışmaya Yönelik Tutum Ölçeğinin Alt Faktörlerinin Açıkladı̆̆ı Variyans Oranları ve Alfa Katsayıları

\begin{tabular}{lll}
\hline Faktör & Açıkladı̆̆ Varyans & Alfa \\
\hline 1.Farkındalık & 30.33 & .85 \\
2.Etki & 14.69 & .80 \\
3.Çekingenlik & 6.83 & .81 \\
Toplam & 51.86 & \\
\hline
\end{tabular}

Tablo 6 incelendiğinde, her bir faktörün açıkladıkları varyans oranı sırasıyla yüzde 30.33, yüzde 14.69, yüzde 6.83 ve toplam 76.5'dir. I. Faktör (Farkındalık) için alfa katsayısı .85 olarak hesaplanırken, aynı katsayı II. Faktör (Etki) için .80, III. Faktör(Çekingenlik) için $.81^{\prime}$ dir. Ölçeğin toplam alfa değeri 0.865 'dir. Alfa 
katsayısının değerlendirilmesinde uyulan değerlendirme kriterleri incelendiğinde $0.00 \leq$ $\alpha \leq 0.40$ ise ölçek güvenilir değildir. $0.40 \leq \alpha \leq 0.60$ ise ölçek düşük güvenirliktedir. $0.60 \leq \alpha \leq 0.80$ ise oldukça güvenilirdir. $0.80 \leq \alpha \leq 1.00$ ise ölçek yüksek derecede güvenilir bir ölçektir (Kalaycı, 2006). Bu durumda Tartışmaya Yönelik Tutum Ölçeği'nin oldukça yüksek güvenilirliğe sahip olduğunu söyleyebiliriz.

\section{Tablo 7}

Tartışmaya Yönelik Tutum Ölçeğinin Alt Faktörlerine İlişkin Ortalama, Standart Sapma, Maksimum, Minimum Puan Değerleri ve Korelâsyon Katsayıları

\begin{tabular}{ccccccccc}
\hline Faktör & $\mathrm{N}$ & $\overline{\mathrm{x}}$ & $\mathrm{SS}$ & $\mathrm{Min}$ & Max & Farkındalı & Etki & Çekingenlik \\
\hline 1.Faktör(Farkındalık) & 200 & 37.99 & 5.53 & 9 & 45 & 1 & $.352^{* *}$ & $.228^{* *}$ \\
2.Faktör(Etki) & 200 & 21.10 & 5.41 & 6 & 30 & $.352^{* *}$ & 1 & $.477 * *$ \\
3.Faktör(Çekingenlik) & 200 & 15.85 & 3.28 & 6 & 22 & $.228^{* *}$ & $.477 * *$ & 1 \\
\hline
\end{tabular}

Tablo 7'de Tartışmaya Yönelik Tutum Ölçeğiyle ilgili korelasyon katsayıları incelendiğinde faktörler arasında anlamlı bir ilişkinin olduğu gözlenmektedir.

Taslak ölçekteki maddeler Tablo 8'de verilmiştir. Tablo 8'de görüldüğü gibi nihai ölçek 20 maddeden oluşmaktadır. Bu maddelerden 10'u olumlu, 10'u olumsuzdur. 


\section{Tablo 8}

Taslak Ölçekte Yer Alan Maddeler ve Faktör Yükleri

\begin{tabular}{|c|c|c|}
\hline 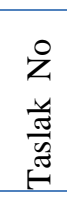 & 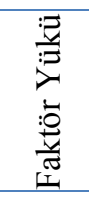 & Ölçekte Yer Alan Maddeler \\
\hline 1 & .632 & Tartışma yöntemi farklı görüşlere tahammül edebilmeyi sağlar. \\
\hline 2 & .599 & Öğretmenle tartışırken kendi hakkımı savunmak hoşuma gider. \\
\hline 3 & .671 & Öğretmenle tartışmak kendimi etkili ve doğru ifade edebilmemi sağlar. \\
\hline 4 & .736 & Öğretmenle tartışmak doğru bildiklerimin kalıcılığını arttırır \\
\hline 5 & .760 & Öğretmenle tartışmak eksik bilgilerimi tamamlamamı sağlar. \\
\hline 6 & .707 & Tartışma bana deneyim kazandırır. \\
\hline 7 & .621 & Tartı̧̧ma dersi sıkıcılıktan kurtarır. \\
\hline 8 & .699 & Öğretmenle tartışmak farklı fikirlerin ortaya çıkmasını sağlar \\
\hline 9 & .629 & Öğretmenle tartışmam sınıfta demokrasi olduğunu gösterir. \\
\hline 10 & .601 & Öğretmenle tartışmam aramızdaki olumlu ilişkiyi zedeler. \\
\hline 11 & .634 & Tartışma yöntemi bana tartışma sanatını öğretmez. \\
\hline 12 & .753 & Öğretmenle tartışırsam konu dağılır. \\
\hline 13 & .719 & Öğretmenimle tartışırsam ona saygısızlık olur. \\
\hline 14 & .748 & Öğretmenimle tartışırsam gergin sınıf ortamından hoşlanmam. \\
\hline 15 & .592 & Öğretmenle tartışarak dikkati üzerime çekmekten hoşlanmam. \\
\hline 16 & .680 & Derste kendimi rahat hissetmediğim için fikrimi söylemem. \\
\hline 17 & .680 & Öğretmenle Tartışmam çünkü o her zaman haklıdır. \\
\hline 18 & .680 & Öğretmenle tartışmam çünkü küçük düşmekten korkarım \\
\hline 19 & .733 & Kendimi bir konu hakkında öğretmenle tartışabilecek kadar yeterli görmüyorum. \\
\hline 20 & .724 & Öğretmenden farklı düşünürsem bu görüşümü ifade etmem. \\
\hline
\end{tabular}

\section{Sonuç ve Tartışma}

$\mathrm{Bu}$ araştırmada, öğretmen adaylarının tartışmaya yönelik tutumlarını belirlemek amacıyla geçerli ve güvenilir bir ölçme aracı hazırlanması amaçlanmıştır. Başlangıçta 57 maddeden oluşan deneme ölçeğinin 200 öğrenciye uygulanmasından sonra yapılan analizler sonucunda 37 maddesi çıkartılarak ölçekte 10'u olumsuz 10'u olumlu olmak üzere toplam 20 madde kalmıştır. Bu maddelerin ölçeğin hazırlanmasında dikkate alınan üç temel yapıyı (farkındalık, etki, çekingenlik) 
yansıttığı görülmüştür. Yapılan analizler sonucunda faktör yük değerlerinin, üç faktör için de .59 ile .76 arasında yüksek düzeyde değiştiği görülmektedir. I. Faktörde (farkındalık) yer alan $(2,3,4,6,7,8,9,12,14)$ maddelere baktığımızda; tartışmaya yönelik "farkındalık" düzeyini ölçtüğü tespit edilmiştir. II. Faktörde (etki) yer alan( 16, 18, 19, 20, 21, 25) maddelere baktığımızda; tartışmaya yönelik "etki” düzeyini ölçtüğü tespit edilmiştir. III. Faktörde (çekingenlik) yer alan (36, 37, 38, 49, 50) maddelere baktığımızda; tartışmaya yönelik "çekingenlik" düzeyini ölçtüğü tespit edilmiştir. Üç faktörlü olarak saptanan ölçeğin her bir alt faktör için madde toplam korelasyonları I. Faktör (farkındalık) için . 59 ile .76; II. Faktör(etki) için .59 ile .74; III. Faktör (çekingenlik) için .68 ile .73 arasında değişmektedir.Belirlenen faktörlerin güvenirlik durumuna bakıldığında I. Faktör (farkındalık) için .85, II. Faktör (Etki) için .80, III. Faktör (Çekingenlik) için .81 olarak belirlenmiştir. $\mathrm{Bu}$ durum ölçeğin yüksek derecede güvenilir olduğunu göstermektedir. “Tartışmaya Yönelik Tutum Ölçeği”ne yapılan geçerlilik ve güvenirlik analizleri sonucunda,öğretmen adaylarının tartışmaya yönelik tutumlarını ölçen, 3 alt boyuttan oluşan geçerli ve güvenilir bir ölçme aracı olarak kabul edilebilir.

Literatürde tartışmaya yönelik tutum ölçeğine rastlanmamıştır ancak tartışmanın özelliklerini taşıyan benzer konularda yapılan ölçek geliştirme çalışmaları incelendiğinde Akın (2007) "Özgüven Ölçeği”nin faktör yüklerinin .31 ile .75 arasında değiştiği; iç tutarlık katsayısı (Cronbach alpha)değerinin .83 olduğu görülmüştür. Acar ve Öğretmen (2007) tarafından geliştirilen "Güvengenlik Ölçeği” nin faktör yüklerinin .32 ile .74 arasında değiştiği; iç tutarlık (Cronbach Alpha)değerinin .87 olduğu ve Yıldız ve Yavuz (2012) tarafından geliştirilen etkili konuşma ölçeğinin iç tutarlık (Cronbach alpha) değerinin .92 olduğu görülmüştür.

Geliştirilen “Öğretmen Adaylarının Tartışmaya Yönelik Tutum Ölçeği”nin faktör yüklerinin. 0.59 ile 0.76 arasında değiştiği, iç tutarlık katsayı (Cronbach alpha) değerinin $\alpha=0.865$ olduğu sonucuna ulaşılmıştır. Buna göre araştırmaya konu edilen ölçeğin faktör dağılımları ve geçerlik-güvenirlik değerleri açısından kullanılabilecek bir yapıda olduğu söylenebilir. Bu ölçek başka araştırmacılar tarafından özellikle DFA (doğrulayici faktör analizi) kullanılarak revize edilebilir. 


\section{Kaynakça}

Acar, V. N.\& Öğretmen, T. (2007). Kendini belirleme (güvengenlik) ölçeği geliştirme çalışmaları. Türk Psikolojik Danışma ve Rehberlik Dergisi, 3(27), 67-78.

Ajzen, I. (1988). Attitudes, personality and behaviour. England: Milton Keynes Open University Press.

Akın, A.(2007). Özgüven ölçeğinin geliştirilmesi ve psikometrik özellikleri. Abant İzzet Baysal Üniversitesi Eğitim Fakültesi Dergisi, 7(2), 167-176.

Allport, G. W. (1954). The nature of prejudice. London: Addison-Wesley.

Anderson, L. W. (1988). Attitudes and their measurement. In J. P. Keeves, (Ed.) Educational Research, Methodology and Measurement. An International Handbook, New York: Pergamon Press.

Bloom, B.S., J.T. Hastings, \& G.F.(1971). Handbook on the formative and summative evaluation of student learning. New York: McGraw-Hill.

Buchanan, L. B. (2011). Discussion in the elementary classroom: how and why some teachers use discussion. The Georgia Social Studies Journal, 1, 19-31.

Büyüköztürk, Ş. (2009). Sosyal bilimler için veri analizi el kitabı. Ankara: Pegem Akademi.

Cashin, W. E., \& McKnight, P. C. (1986). Improving discussions. Kansas State University.

Costello, B. A. \& Osborne, J.W. (2005). Best practices in exploratory factor analysis: four recommendations for getting the most from your analysis. Practical Assessment Research Evaluation, 10 (7), 1-9.

Cureton, E. E.\& D’Agostino, R.B. (1983). Factor analysis an applied approach. Broadway: Lawrence Erlbaum Associates, Inc. Publishers.

Çepni,S. (2005). Araştırma ve proje çalışmalarına giriş. Trabzon: Tused

Dorn, M. C., Madeja, S. S.\& Sobal, R. F. (2004). Assessing expressive learning. London: LEA Publishers.

Eagley, A.H. \& Chaiken, S. (1998). Attitude change: multiple roles for persuasion variables. In D.T. Gilbert, S.T. Fiske, \& G. Lindzey (Eds.), The Handbook of Social Psychology 2. New York: McGraw- Hill.

Fishbein, M. \& Ajzen, I. (1975). Belief, attitude, intention, and behavior: An introduction to theory and research. Reading, MA: Addison-Wesley.

Gall, M. D., \& Gillett, M. (1980). The discussion method in classroom teaching. Theory into Practice, 19, 98-103.

Gamst, G. Meyers, L. S., \& Guarino, A.J. (2008). Analysis of variance designs: A conceptual and computational approach with SPSS and SAS. New York: Cambridge University Press.

Green, B. S. \& Salkind, J. N. (2005). Using SPSS for windows and understanding data (Fourth Edition). New Jersey: Pearson Education. 
Green, C. F., Christopher, E. R. \& Lam, J. (1997). Developing discussion skills in the ESL classroom. ELT Journal, 51(2), 135-141.

Hadjioannou, X. (2007). Bringing the background to the foreground:what do classroom environments that support authentic discussions look like? American Educational Research Journal, 44(2), 370-399.

Howell, M. G. (2008). Does discussions help stundents analyze data? (Master Thesis). University of California Davis, California.

Henning, J. E. (2008). The art of discussion based teaching opening up conversation in the classroom. Newyork: Routledge.

Kalaycı, Ş.(2006). SPSS uygulamalı çok değişkenli istatistik teknikleri. (2.Baskı). Ankara: Asil Yayın.

Karasar, N.(2006). Bilimsel araştırma yöntemi. Ankara: Nobel yayın Dağıtım.

Kline, P. (1994). An easy guide to factor analysis. New York: Routledge.

Marsh, H. W. \& Yeung, A.S. (1999).The lability of psychological ratings: The chameleon effect in global self-esteem. Personality \& Social Psychology Bulletin, 25, 49-64.

Mok, M. C.\& Lung, L. C. (2005). Developing self-directed learning in student teachers. International Journal of Self Directed Learning, 18-39.

Murphy, K. P.,Soter, A.O.,Wilkinson, I. A. G.,Hennessey, M. N.\& Alexander, J. F. (2009). Examining the effects of classroom discussion on students' comprehension of text: A Meta-Analysis. Journal of Educational Psychology, 101(3), 740-764.

Tavşancil, E. (2006). Tutumların ölçülmesi ve SPSS ile veri analizi. Ankara: Nobel Yayın.

Tekindal, S. (2009). Duyuşsal özelliklerin ölçülmesi için araç oluşturma. Ankara: Pegem Akademi.

Tezbaşaran, A. A. (1996). Likert tipi ölçek geliştirme kllavuzu. Ankara: TPD Yayınları.

Tezbaşaran, A.A. (1997). Likert tipi ölçek geliştirme kılavuzu. Ankara: Türk Psikologlar Derneği.

Yıldız, Ç. D. \& Yavuz, M. (2012). Etkili konuşma ölçeği: bir ölçek geliştirme çalışmas1, Turkish Studies - International Periodical For The Languages, Literature and History of Turkish or Turkic Volume, 7(2), 319-334.

Wenden, A. (1998). Learner Strategies for Learner Autonomy. London: Prentice Hall. 